Orthopäde $2017 \cdot 46: 85-89$

DOI 10.1007/s00132-016-3349-3

Published online: 17 November 2016

(c) The Author(s) 2016. This article is available at SpringerLink with Open Access.

CrossMark

Qi Lai ${ }^{1,2} \cdot$ Yuan Liu ${ }^{1,2} \cdot$ Xionglong Yu ${ }^{1,2} \cdot$ Xin Lv ${ }^{1,2} \cdot$ Qiang Wang ${ }^{1,2} \cdot$ Yibiao Zhou $^{1,2}$. Runsheng Guo ${ }^{1,2} \cdot$ Bin Zhang ${ }^{1,2}$

'Department of Orthopedics, Artificial Joints Engineering and Technology Research Center of Jiangxi Province, The First Affiliated Hospital of Nanchang University, Nangchang, China

${ }^{2}$ Multidisciplinary Therapy Center of Musculoskeletal Tumor, The First Affiliated Hospital of Nanchang University, Nangchang, China

\title{
Diagnosis and treatment of nonadjacent cryptococcal infections at the L1 and S1 vertebrae
}

Hospital of Nanchang University Medical School.

A 25-year-old man presented with a 1month history of spinal osteosarcoma that was misdiagnosised at a local county hospital, as well as a 5-week history of progressive lower back pain and occasional pain radiating to the left lower limb. The patient had no other medical history. A general physical examination and central nervous system examination upon patient admission revealed normal findings. His erythrocyte sedimentation rate (ESR) was $14 \mathrm{~mm} / \mathrm{h}$ (normal: $0-20 \mathrm{~mm} / \mathrm{h}$ ) and his C-reactive protein (CRP) levels were $11.2 \mathrm{mg} / \mathrm{l}$ (normal: $0-5.0 \mathrm{mg} / \mathrm{l}$ ); all other blood test findings were normal.

Transverse computed tomography (CT) revealed nonadjacent low-intensity lesions with clear boundaries at L1 and S1 (• Fig. 1). Lumbar vertebra magnetic resonance imaging (MRI; - Fig. 2) also revealed that the left half of the L1 vertebral body had been destroyed and that the S1 lesion extended into the soft tissues. A whole-body bone scan (- Fig. 3) revealed generally clear results, although the L1 and S1-S2 vertebrae exhibited abnormal bone densities, which indicated the possibility of bone tumor. All of these findings indicated a malignant tumor, but the type of tumor could not be diagnosed clearly and needed further examination.
Three days after the admission, the patient experienced night-time fever, and blood tests revealed a white blood cell count of $10.2 \times 10^{9} / \mathrm{l}$, an ESR of $46 \mathrm{~mm} / \mathrm{h}$, and CRP levels of $27.3 \mathrm{mg} / \mathrm{l}$. Based on these findings, the patient agreed to undergo an S1 vertebra puncture biopsy. The biopsy results revealed an infected lesion with massive neutrophil infiltration, and we started treating the patient using intravenous moxifloxacin and teicoplanin. However, the patient continued to exhibit pain radiating to the left lower limb, a fever of up to $39.8^{\circ} \mathrm{C}$, an ESR of $62 \mathrm{~mm} / \mathrm{h}$, and CRP levels of $44 \mathrm{mg} / \mathrm{l}$. Therefore, we performed lumbosacral debridement under general anesthesia, and obtained intra-operative purulent tissue specimens for pathological examination and microbial culture. The operative finding was that the $\mathrm{S} 1$ to the sacroiliac joint contained a $5 \times$ 6-cm lesion with a large amount of pus. Thus, the surgeons used a spatula to reduce the lesion, along with physiological saline and iodine, and ultimately used a gelatine sponge with vancomycin to fill the cavity. The postoperative pathology report identified inflammatory changes at L1 and S1, which indicated a fungal infection (- Fig. 4). The tissue and blood specimens were sent to the Shanghai Huashan Hospital for microbial identification and drug susceptibility testing, which revealed a cryptococcal infection that was sensitive to amphotericin B.
Runsheng Guoand Bin Zhang: These authors are joint senior authors on this work and should be regarded as co-correspondence. 


\section{Kasuistik}
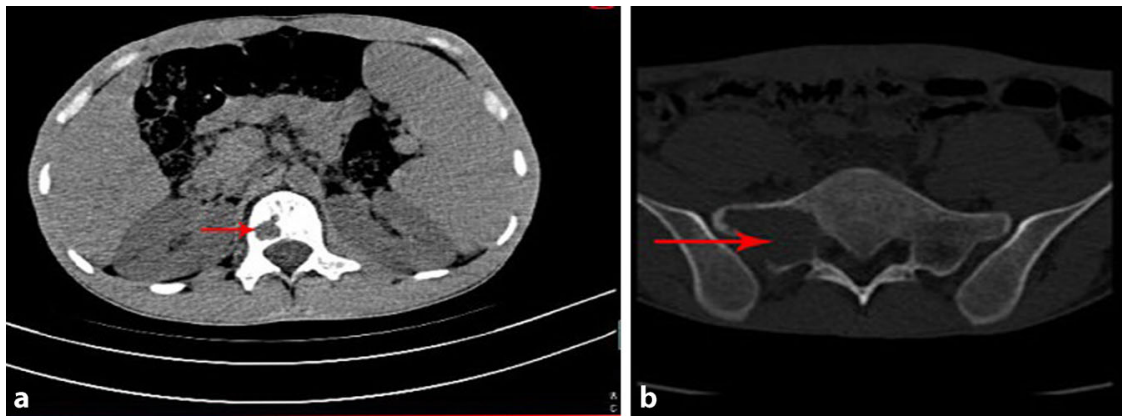

Fig. $1 \Delta$ Preoperative computed tomography of $\mathrm{S} 1$ and $\mathrm{L} 1$ reveals bone destruction and vertebral abnormalities. a L1 Vertebral lesions and vertebral invasion. bS1 Vertebral lesions and vertebral invasion. Red arrows indicate location and extent of the lesions

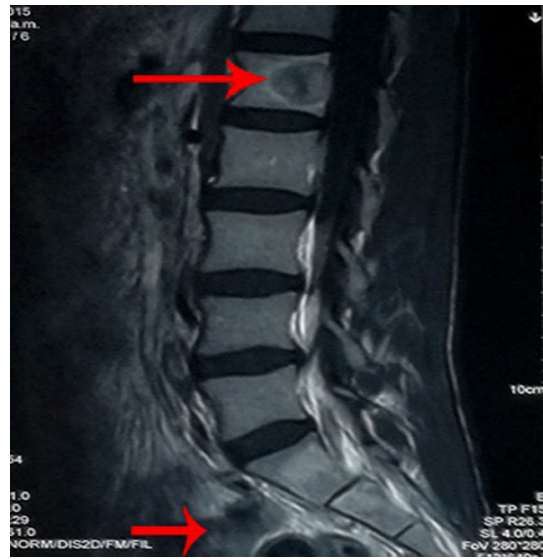

Fig. $2 \Delta$ Preoperative magnetic resonance imaging of $\mathrm{L} 1$ and $\mathrm{S} 1-\mathrm{S} 2$ reveals bone destruction and vertebral abnormalities. Red arrows indicate L1 (upper arrow) and S1-S2 (lower arrow) lesions in MR

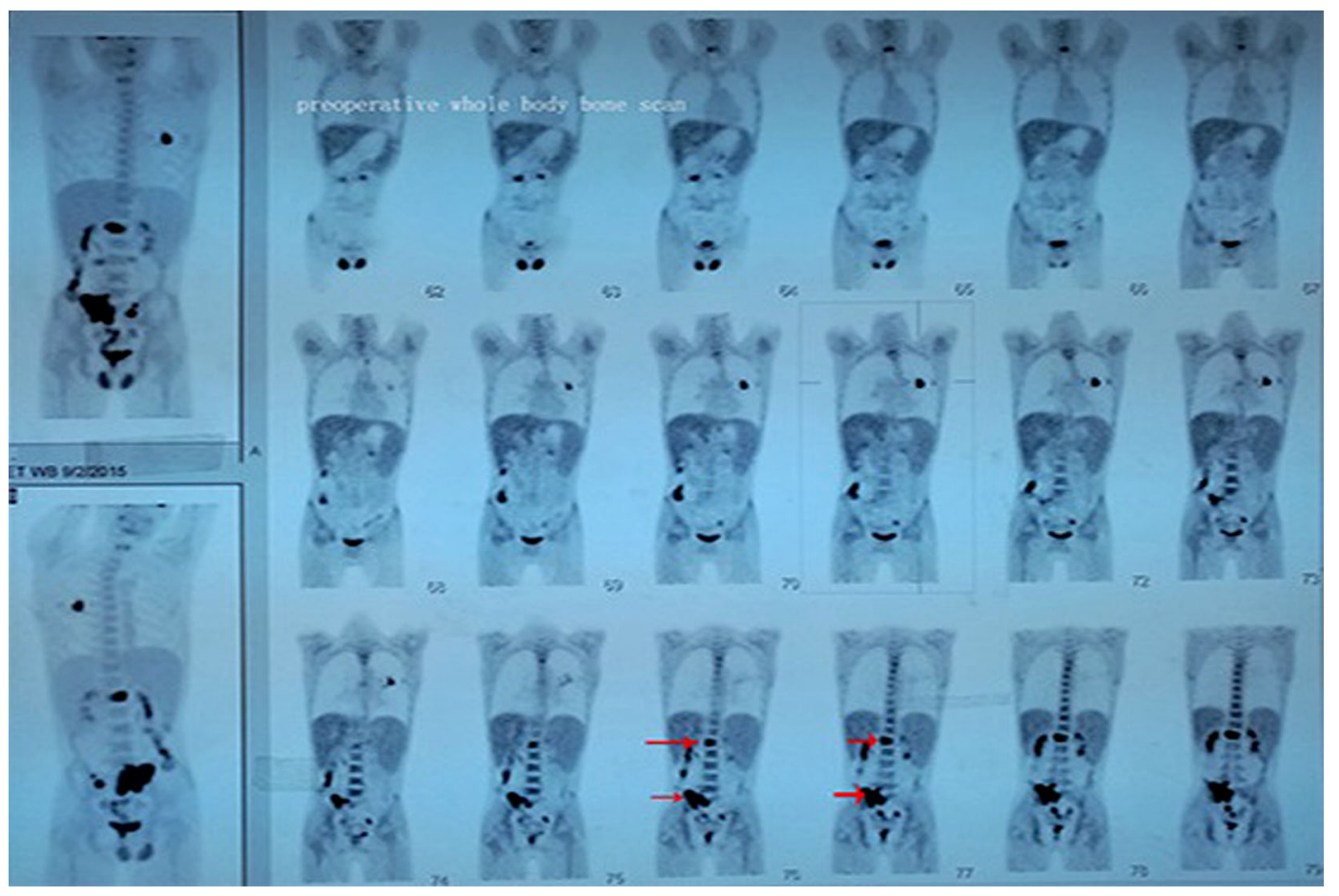

Fig. $3<$ A preoperative whole-body bone scan reveals abnormal bone densities at L1 and S1-S2, which indicated metastatic tumors. Red arrows show extent of invasion of lesions in whole-body bone scan
Therefore, we treated the patient using 4 weeks of intravenous amphotericin B ( $80 \mathrm{mg} /$ day) and then 8 weeks of oral amphotericin B (60 mg/day). The patient did not report lower back pain or symptoms of recurrence at the 3-month follow-up, and his body temperature, blood results, ESR, and CRP levels were normal. The patient also did not exhibit any symptoms of recurrence or abnormal imaging findings at the 9-month followup (• Fig. 5).

\section{Discussion}

Spinal infections are common and are mainly observed in cases of tuberculosis [1] or postoperative infection. In contrast, fungal osteomyelitis is a rare spinal infection [2] and is typically caused by Aspergillus (38.2 \%) or Candida (22.9\%) [3]. Furthermore, cryptococcal lumbosacral vertebra infections are extremely rare. The first reported case of a fungal spine infection involved blastomycosis [4], and Eisen et al. [5] reported the first case of cryptococcosis with lung and spine involvement in 1955. Since 1955, some researchers have reported fungal spine infections (typically involving Aspergillus or Candida), although no reports described cryptococcal infections until a 2013 study by Zhou et al. [6], who examined cryptococcal lumbar infections in patients with rheumatoid arthritis. Furthermore, Wang et al. [7] described the imaging findings of cryptococcal thoracic spine infections. Based on these characteristics, numerous researchers 
[1-5] believe that cryptococcosis mainly occurs in the central nervous system and lungs of immunocompromised hosts and can involve any body site or structure. Moreover, researchers generally consider cryptococcal spine infections as a rare and opportunistic infectious disease that should be treated using conservative methods.

In the present case, we encountered a 25-year-old generally healthy man with newly diagnosed cancer and back pain, which we ultimately identified as being related to a cryptococcal infection. Therefore, it appears that otherwise healthy individuals may be vulnerable to these infections, despite the consensus opinion that primary fungal infections are limited to patients with immunodeficiency or immunosuppression [8]. Furthermore, Wong et al. [9] reported that patients rarely exhibit fungal spine infections if they do not have immunodeficiency factors or primary infected lesions, and most cases of cryptococcal spine infections among healthy people are likely misdiagnosed as cancer or tuberculous granuloma. Moreover, Lzzati et al. [10] and others believe that approximately $25 \%$ of spinal infections occur in cases with no means of obtaining a bacteriological diagnosis. Similarly, orthopedic surgeons and radiologists can attempt noninvasive radiological examinations to confirm a fungal spine infection, but there have not been any breakthroughs in this field. Sobottke et al. [11] evaluated the diagnostic value of positron emission tomography, although this modality provided minimal value for diagnosing idiopathic fungal spine infections. Therefore, many patients are not diagnosed at a stage that would facilitate conservative treatment and must undergo surgery.

In the present case, we originally considered the possibility of a spinal tumor, and only identified the fungal infection after we performed S1 biopsy and lumbosacral debridement. Thus, an early diagnosis can only be achieved through clinician awareness, a detailed medical history, a careful physical examination, relevant laboratory testing, and imaging findings. We also suggest that, in cases with suspicious symptoms, patients

Orthopäde 2017 ·46:85-89 DOI 10.1007/s00132-016-3349-3

(c) The Author(s) 2016. This article is available at SpringerLink with Open Access.

\section{Q. Lai · Y. Liu · X. Yu · X. Lv · Q. Wang · Y. Zhou · R. Guo · B. Zhang}

\section{Diagnosis and treatment of nonadjacent cryptococcal infections at the L1 and S1 vertebrae}

\begin{abstract}
Cryptococcal spine infections are rare infections that are easy to misdiagnose and difficult to cure. Therefore, we report the case of a 25 -year-old man who presented with nonspecific spinal lesions at L1 and S1. The patient underwent surgical removal of the lesions, and specimens were submitted for microbial identification, which identified a cryptococcal infection that was susceptible to amphotericin B. The patient exhibited marked improvement after receiving
\end{abstract}

intravenous amphotericin $B$ and remained asymptomatic (no back pain, fever, or other symptoms) at the 3-and 9-month follow-ups. Similar cases of cryptococcal spine infections are rare, and we believe that our diagnostic findings and treatment experience may help improve the management of this rare disease.

Keywords

Cryptococcosis - Bacterial infections and mycoses - Bone diseases - Cancer - Spine

\section{Diagnose und Behandlung von nichtbenachbarten Kryptokokkeninfektionen an den Wirbeln L1 und S1}

\section{Zusammenfassung}

Kryptokokkeninfektionen an der Wirbelsäule sind selten. Sie sind nicht einfach zu diagnostizieren und schwierig zu behandeln. Aus diesem Grund berichten die Autoren über den Fall eines 25-jährigen Mannes, der sich mit unspezifischen Wirbelläsionen im Bereich L1 und S1 vorstellte. Der Patient unterzog sich einer chirurgischen Entfernung der Läsionen. Es erfolgte eine mikrobiologische Untersuchung von Proben, bei welcher eine Kryptokokkeninfektion identifiziert wurde, die auf Amphotericin B anspricht. Der Zustand des Patienten verbesserte sich deutlich nach der intravenösen Gabe von Amphotericin B, und es traten bei den Nachsorgeuntersuchun- gen nach 3 und 9 Monaten keine weiteren Symptome auf (kein Rückenschmerz, Fieber oder andere Symptome). Ähnliche Fälle von Kryptokokkeninfektionen an der Wirbelsäule sind selten. Die Autoren sind der Meinung, dass ihre Erfahrung mit den diagnostischen Ergebnissen und der Therapie dabei helfen kann, das Krankheitsmanagement dieser seltenen Erkrankung zu verbessern.

\section{Schlüsselwörter}

Kryptokokkose · Bakterielle Infektionen und Mykosen · Knochenerkrankungen · Krebs · Wirbelsäule should quickly undergo testing for procalcitonin levels, ESR, CRP levels, and spinal MRI. This is because spinal infections are characterized by an elevated ESR (sensitivity: 76-81 \%) [12], elevated CRP levels (sensitivity: 90-93\%) [13], and elevated procalcitonin levels (sensitivity: 95-97 \%) [13]. Procalcitonin testing is especially sensitive at the early stage, and MRI is also widely used to evaluate inflammation in the vertebral body and disk, as Modic et al. [14] found that MRI provided a sensitivity of $96 \%$ for identifying vertebral osteomyelitis. Moreover, if the results of these tests indicate a spinal infection, puncture biopsy and culturing should be immediately performed to confirm the diagnosis. If the results suggest a fungal infection, the fungus should be identified and the fungal spores viewed under a microscope [15]. This is because the histological findings of cryptococcal spine infections are nonspecific (e. g., a sequestrum and/or abscess), and visual evaluation of the spores is essential for diagnosing a cryptococcal spine infection. Therefore, biopsy, microbial culture, and fungal spore examination can help identify the fungus, and then antifungal therapy should be implemented as soon as possible.

In the present case, the patient underwent surgical removal of the spinal lesions, with postoperative saline irrigation for 1 week and removal of specimens for pathological examination and 

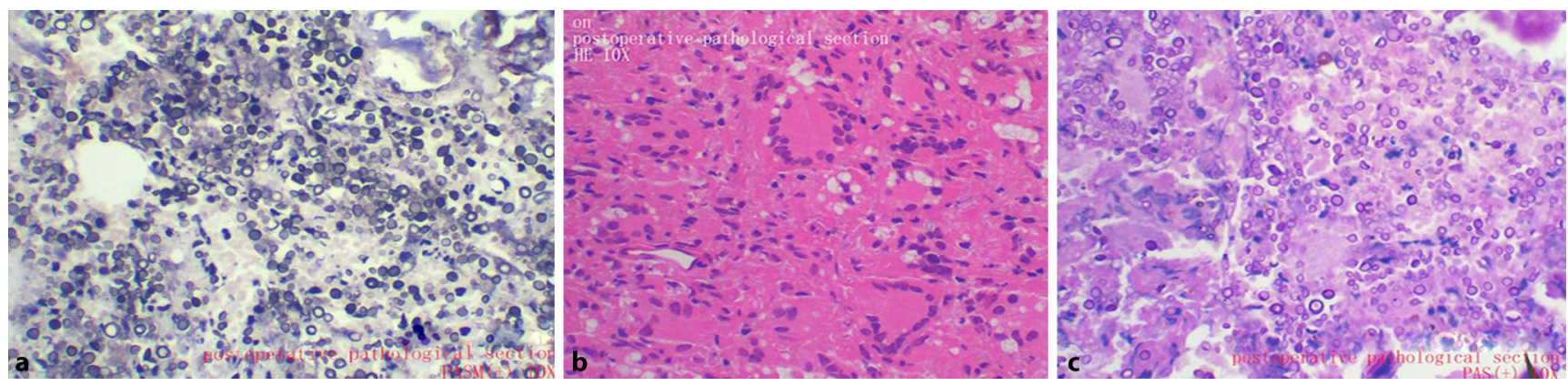

Fig. 4 \ Postoperative pathology reveals epithelioid cells and multinucleated giant cell granuloma formation, with significant caseous necrosis, granuloma, and a diffuse oval body with refraction around the crassicarpa membrane. Positive periodic acid-Schiff (PAS) and periodic acid-silver methenamine (PASM) results indicate a fungal infection. a PASM is positive. $b$ pathological results: fungal infection. c positive periodic acid-schiff (PAS $(+))$

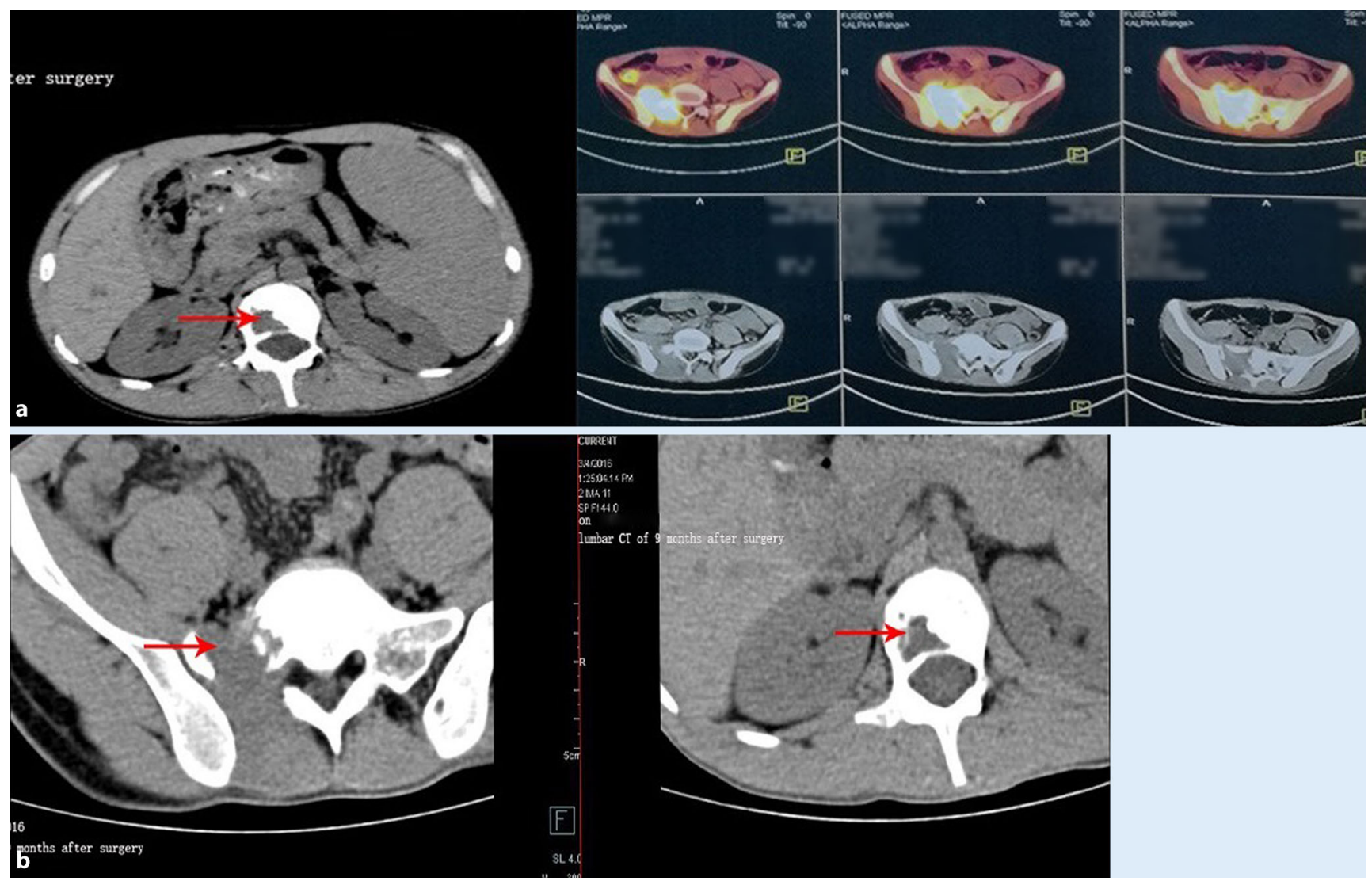

Fig. $5 \Delta$ Computed tomography at a 3 months and b 9 months reveals no symptoms of recurrence and no changes in the lesions. Red arrows show improvement of lesions at 3-month and 9-month follow-up

microbial culture. These tests revealed a fungal infection (• Fig.5), and fungus identification and drug susceptibility experiments ultimately identified a cryptococcal infection that was sensitive to amphotericin B. The patient's symptoms significantly improved after 4 weeks of intravenous amphotericin $\mathrm{B}$, and we observed obvious decreases in the values for ESR, CRP, and procalcitonin. Therefore, we provided oral amphotericin $\mathrm{B}$ for 8 weeks after the patient's discharge, and at the 3-month and 9-month followups no symptoms of recurrence or lesion proliferation were detected.

\section{Conclusion}

We encountered a 25-year-old man with a rare cryptococcal spine infection that presented as newly diagnosed cancer and lower back pain. This case indicates that this infection should be considered in endemic regions, among immunodeficient patients, and also in the normal population. However, the symptoms of cryptococcosis are atypical and difficult to diagnose using a simple physical examination; therefore, biopsy, microbial culture, and fungal spore evaluation are essential steps that are needed to make a definitive diagnosis. Murray et al. [16] recommended 12 weeks of intravenous 
voriconazole and oral fluconazole for the treatment of fungal infections, although we recommend that cases of spinal cryptococcosis with an early diagnosis should treat using 12 weeks of amphotericin B (4 weeks of intravenous amphotericin B and 8 weeks of oral amphotericin B). Moreover, surgical treatment with postoperative physiological saline irrigation for 7-12 days [17] should be considered in cases without an early diagnosis, with delayed treatment, with severe symptoms, or cases that are not appropriate for conservative treatment.

\section{Corresponding address}

\section{R. Guo}

Department of Orthopedics, Artificial Joints Engineering and Technology Research Center of Jiangxi Province, The First Affiliated Hospital of Nanchang University 330006 Nangchang, Jiangxi, China 36882067@qq.com

\section{B. Zhang}

Department of Orthopedics, Artificial Joints Engineering and Technology Research Center of Jiangxi Province, The First Affiliated Hospital of Nanchang University 330006 Nangchang, Jiangxi, China 15879177108.@163.com

Acknowledgements. The authors would like to thank the patient for providing us with informed written consent for publication of this case study. The authors would like to thank Bin Zhang and Rensheng Guo for their secretarial assistance. The authors thank Bin Zhang and Rensheng Guo for their theoretical and clinical guidance.

Funding. All research costs were covered by two projects: Jiangxi Province Health Department of Science and Technology Plan (20155195) and Jiangxi Science and Technology Support Plan (20151122070282)

\section{Compliance with ethical guidelines}

Conflict of interest. Q. Lai, Y. Liu, X. Yu, X. Lv, Q. Wang, Y. Zhou, R. Guo, and B. Zhang declare that they have no competing interests.

All procedures performed in studies involving human participants were in accordance with the ethical standards of the institutional and/or national research committee and with the 1964 Helsinki declaration and its later amendments or comparable ethical standards. Informed consent was obtained from all individual participants included in the study.

Open Access. This article is distributed under the terms of the Creative Commons Attribution 4.0 International
License (http://creativecommons.org/licenses/by/ 4.0/), which permits unrestricted use, distribution, and reproduction in any medium, provided you give appropriate credit to the original author(s) and the source, provide a link to the Creative Commons license, and indicate if changes were made.

\section{References}

1. Zhang Z, Luo F, Zhou Q, Dai F, Sun D, Xu J (2016) The outcomes of chemotherapy only treatment on mild spinal tuberculosis. J Orthop Surg Res. doi:10. 1186/s13018-016-0385-y

2. Dimar JR, Puno RM, Nowacki MR, Carreon LY (2014) Surgery for blastomycosis of the spine. Am J Orthop 43:E266-E271

3. Ganesh D, Gottlieb J, Chan S, Martinez O, Eismont $F$ (2015) Fungal infections of the spine. Spine 40:E719-E728

4. Voris HC, Greenwood RC (1947) Blastomycosis of the spine with invasion of the spinal canal. Proc Inst Med Chic 16:463-415

5. Eisen D, Shapiro I, Fischer JB (1955) A case of cryptococcosis with involvement of lungs and spine. Can Med Assoc J 72(1):33-35

6. Zhou HX, Ning GZ, Feng SQ, Jia HW, Liu Y, Feng HY, Ruan WD (2013) Cryptococcosis of lumbar vertebra in a patient with rheumatoid arthritis and scleroderma: case report and literature review. BMCInfect Dis 13(7):128. doi:10.1186/1471-233413-128

7. Wang C, Jia N, Zhang L, Liu K, Liu H, Yu H (2014) Imaging findings of cryptococcal infection of the thoracic spine. Int J Infect Dis 29:162-165. doi:1016/j.ijid.2014.07.013

8. Lado FL, Villamil Cajoto I, Rodrfguez Constenla I et al (2005) Spondylodiskitis caused by Candida alhicans. Report of two new cases. An Med Interna 22(2):76-78

9. Wong NM, Sun LK, Lau PY (2008) Spinal infection caused by my cobacterium avium complex in a patient with no acquired immune deficiency syndrome: a case report. J Orthop Surg (Hong Kong) 16(3):359-363

10. Lzzati R, Giacomazzi D, Danzi MC et al (2009) Diagnosis, management and outcome clinically suspected spinal infection. JInfect 58(4):259-265

11. Sobottke R, Zarghooni K, Seifert $H$ et al (2008) Spondylodiscitis eaused by mycobacterium xenopi. Arch Orthop Trauma Surg 128(10):1047-1053

12. James SL, Davies AM (2006) Imaging of infectious spinal disorders in children and adults. Eur J Radio 58:27-40

13. Kiertiburanakul S, Wirojtananugoon S, Pracharktam R, Sungkanuparph S (2006) Cryptococcosis in human immunodeficiency virus negative patients. Int JInfect Dis 10:72-77

14. Modic MT, Feiglin DH, Piraino DW, Boumphrey F, Weinstein MA, Duchesneau PM et al (1985) Vertebral osteomyelitis: assessment using MR. Radiology 157:157-166

15. Gupta SK, Chhabra R, Sharma BS (2003) Vertebral cryptococcosis simulating tuberculosis. $\mathrm{Br} J$ Neurosurg 17:556-571

16. Murray MR, Schroeder GD, Hsu WK (2015) Granulomatous vertebral osteomyelitis: an update. J Am Acad Orthop Surg 23:529-538

17. Ahmed R, Greenlee JD, Traynelis VC (2012) Preservation of spinal instrumentation after development of postoperative bacterial infection in patients undergoing spinal arthrodesis. J Spinal Disord Tech 25(6):299-302
Spielkonsole als Therapieoption bei RA

Wenn Patienten aus Zeitgründen oder einer schlechten Erreichbarkeit einer physiotherapeutischen Praxis kaum noch körperlich aktiv sind, dann können animierte Heimübungsprogramme unter Nutzung einer Spielkonsole zur Bewegungsförderung beitragen. Der motivierende Aspekt der Konsole spielt eine zentrale Rolle, unabhängig vom Patientenalter und der Krankheitsdauer.

Übungsprogramme an einer Spielkonsole können eine alternative, unterstützende Option für Patienten mit rheumatoider Arthritis (RA) sein, wie Wissenschaftler der Charité - Universitätsmedizin Berlin jetzt in einer Pilotstudie herausgefunden haben.

Ausschließlich Patienten mit einer RA mit niedriger Krankheitsaktivität unter Therapie mit einem biologischen Basismedikament sind in die Untersuchung einbezogen worden. Nach einer Einführung in das eigenständige Training haben 15 Patienten mit einem konventionellen heimbasierten physiotherapeutischen Übungsprogramm und weitere 15 Patienten mit einem definierten animierten Übungsprogramm an einer Spielkonsole begonnen. Nach zwölf Wochen wechselten die Patienten in die jeweils andere Behandlungsgruppe für weitere zwölf Wochen.

Beide Gruppen wiesen nach dem Therapiezeitraum die gleichen Verbesserungen in den physiologischen Funktionstests aus. Die Gesamtmuskelkraft stieg um etwa zwölf Prozent an und die Gehleistung erhöhte sich um durchschnittlich fünf Prozent. Die Vorteile der zeitlichen Flexibilität und der unterhaltsamen Ausführung scheinen den Nachteil der nicht angeleiteten und möglicherweise nicht optimalen Bewegungsausführung auszugleichen.

Literatur: J. Zernicke et al (2016)

BMC Musculoskeletal Disorders.17(1):351.

Quelle: Charité - Universitätsmedizin Berlin, www.rheumatologie.charite.de/ 